\title{
1 OPINION
}

\section{Can biomass supply meet the demands of BECCS?}

3

4
Michael B. Jones ${ }^{1}$ and Fabrizio Albanito ${ }^{2}$

${ }^{1}$ Botany Department, School of Natural Sciences, Trinity College Dublin, University of Dublin, Dublin 2, Ireland

${ }^{2}$ Institute of Biological and Environmental Sciences, University of Aberdeen, 23 St Machar Drive, Aberdeen, AB24 3UU, UK

Correspondence: Michael B. Jones, Botany Department, School of Natural Sciences, Trinity College Dublin, Dublin 2, Ireland. Email: mike.jones@tcd.ie

\section{Abstract}

In order to reach the reduced carbon emission targets proposed by the Paris agreement one of the widely proposed decarbonizing strategies, referred to as negative emissions technologies (NETs), is the production and combustion of bioenergy crops in conjunction with carbon capture and storage (BECCS). However, concerns have been increasingly raised that relying on the potential of BECCS to achieve negative emissions could result in delayed reductions in gross $\mathrm{CO}_{2}$ emissions, with consequent high-risk of overshooting global temperature targets. We focus on two particular issues; the carbon efficiency and payback time of bioenergy use in BECCS and the potential constraints on the supply of bioenergy. The simplistic vision of BECCS is that one ton of $\mathrm{CO}_{2}$ captured in the growth of biomass equates to one ton of $\mathrm{CO}_{2}$ sequestered geologically, but this cannot be the case as $\mathrm{CO}_{2}$ is emitted by variable amounts during the life cycle from crop establishment to sequestration below ground in geological formations. The deployment of BECCS is ultimately reliant on the availability of sufficient, sustainably sourced, biomass. The two most important factors determining this supply are land availability and land productivity. The upper bounds of the area estimates required correspond to more than the world's harvested land for cereal production. To achieve these estimates of biomass availability requires the rapid evolution of a multitude of technological, social, political, and economic factors. Here, we question whether, because of the limited sustainable supply of biomass, BECCS should continue to be considered the dominant NET in IPCC and other scenarios achieving the Paris targets, or should it be deemed no longer fit for purpose?

\section{Introduction}


Negative emissions technologies (NETs) are any process that removes carbon dioxide from the atmosphere and stores it in the biosphere or geosphere. In recent years, the international research on NETs has grown rapidly and publications have ranged in scope from reviewing the potential of NETs in climate change mitigation scenarios, to assessing the feasibility of achieving technological maturity and discussing deployment opportunities (Minx et al., 2017). However, concerns have been increasingly raised that ungrounded optimism in NETs potential could result in delayed reductions in gross $\mathrm{CO}_{2}$ emission, with consequent high-risk of overshooting of global temperature targets (Kato \& Yamagata, 2014; Fuss et al., 2014; Anderson \& Peters, 2016; Vaughan et al., 2018). In order to reach the reduced carbon emission targets proposed by the Paris agreement, one of the widely proposed NETs is the production and combustion of forest products or second-generation bioenergy crops in conjunction with carbon capture and storage (BECCS). Most Integrated Assessment Models (IAMs) suggest that BECCS will make a significant contribution to NETs in the near to mid-term future and it has come to be viewed as the key $\mathrm{CO}_{2}$ removal approach to keep global atmospheric $\mathrm{CO}_{2}$ concentrations below $500 \mathrm{ppm}$ and avoid catastrophic climate change (Fuss et al., 2018; Nemet et al., 2018; NAS, 2018). The reason why BECCS plays such a pervasive and pivotal role in climate change mitigation pathways is based on an assumption that large areas of land could be made available for bioenergy production at scale and that bioenergy is in the near term a relatively low-cost and lowemission source of energy (EASAC, 2018; Reid, Ali \& Field, 2019).

Negative emissions as a consequence of BECCS is achieved when the $\mathrm{CO}_{2}$ absorbed from the atmosphere during the growth cycle of biomass is released in combustion and energy production and then captured and stored indefinitely (Kemper, 2015). The simplistic vision of BECCS is that one ton of $\mathrm{CO}_{2}$ captured in the growth of biomass equates to one ton of $\mathrm{CO}_{2}$ sequestered geologically. However, biomass crops are not carbon neutral because GHG emissions are associated with the cultivation of biomass and furthermore GHG emissions occur throughout the BECCS value chain which reduces the carbon efficiency (Brandao et al., 2018; Tanzer \& Ramirez, 2019).

Gough et al. (2018) identified a number of policy and governance challenges associated with the deployment of BECCS, including whether BECCS can be delivered at sufficient scale and also be provided sustainably. Here we suggest that it is becoming increasingly clear that the potential of BECCS is significantly constrained by a combination of socio-political, technical and geographic considerations, including limits to knowledge and experience (Fridahl \& Lehtveer, 2018), and ask whether BECCS should continue to be the dominant NET in IPCC and other scenarios achieving Paris targets or should it be deemed no longer fit for purpose. We highlight two particularly important issues, the low carbon efficiency and long payback time of biomass for BECCS and the potential constraints on the supply of biomass for bioenergy. 


\section{Carbon efficiency of BECCS}

The first impact of displacing fossil fuel with biomass for power generation in BECCS is a carbon debt derived from an increase in atmospheric $\mathrm{CO}_{2}$ emission from land clearing and biomass production (i.e. direct land use emissions), harvesting, transport and processing (i.e. lifecycle emissions), as well as stack emissions due to higher $\mathrm{CO}_{2}$ emissions from biomass combustions relative to continued fossil fuel use. The size of the bioenergy carbon debt depends also on how far upstream and downstream emissions are estimated within the system boundary of any life cycle analysis (LCA) (Tanzer \& Ramirez, 2019). Studies including only a gate-to-gate boundary system ignore land-based emissions and assume that the amount $\mathrm{CO}_{2}$ removed by biomass from the atmosphere is equal to the $\mathrm{CO}_{2}$ emitted from its combustion (i.e. the bioenergy is "carbon neutral"). These studies in general provide optimistic results on the potential savings from bioenergy crops. Since bioenergy systems involve land-based and lifecycle emissions, a further expansion of the boundaries is needed to encompass a "cradle-to-gate" boundary system which includes upstream emissions (Hastings, 2017, Roder et al., 2015). Ultimately, LCAs should include both upstream and downstream emissions in a "cradle-to-grave" determination of the overall climate mitigation of NETs (Tanzer \& Ramirez 2019) (Figure 1).

Life cycle GHG assessments have shown that the differences in supply chain emissions from biomass cultivation, harvesting and transportation can be relatively small compared to the large differences in combustion and processing efficiencies of the power plants (Odeh \& Cockerill 2008, Roder et al., 2015). This is because, at the point of combustion, biofuels generate more $\mathrm{CO}_{2}$ per unit of end-use energy than fossil fuels. Although woody biomass has approximately the same carbon intensity as coal $(0.027$ vs. $0.025 \mathrm{tC} / \mathrm{GJ}$ of primary energy), combustion efficiency of wood and wood pellets is in general lower than fossil fuels with typical combustion efficiencies for wood being approximately $25 \%$, compared to $35 \%$ for coal (IEA 2016). Published estimates vary with the process examined, but energy processing losses for the wood pellet supply chain are on the order of approximately $27 \%$ if biomass is used in the drying process (Roder et al., 2015), compared to losses of approximately $11 \%$ for coal (IEA, 2016). In addition, capturing the $\mathrm{CO}_{2}$ and then compressing it prior to transport produce an energy penalty that needs to be accounted for in the overall boundary system of BECCS. Additional energy is required to extract the steam needed for the $\mathrm{CO}_{2}$ absorber/stripper system, to scrub the $\mathrm{CO}_{2}$ due to compressing the flue gas and pumping the solvent, and finally to compress the recovered $\mathrm{CO}_{2}$ prior to belowground storage sequestration.

\section{Carbon payback time}

The carbon payback time of biofuels is the number of years it can take to offset the carbon emissions generated by converting land for biofuels. Biofuels can only reduce 
atmospheric $\mathrm{CO}_{2}$ over time by increasing net primary productivity above what it otherwise would have been. This period is very sensitive to the type of biomass crop and previous land use, and can range from less than 10 years for perennial grasses to over 100 years for slow growing clear-felled forests. Estimates of the payback time of biomass-fired power plants are limited, but have been reported as high as 400 years (Bentsen 2017). Depending on the land use change, the land-based production system and fossil fuel replaced, the payback time of the carbon debt of wood pellets is found to vary from 44 to $>104$ years to offset coal (Sterman et al., 2018). Pellets from residues are reported to have a temporal lags against coal-fired generation of approximately 16 years, while pellets from standing tree harvesting would require 35-50 years to reach a payback (McKechnie et al., 2011). It is also important to recognise that BECCS negative emissions are not delivered from year one and a time lag will occur before the initial extra emissions from producing the crop and establishing the BECCS facility are recovered.

\section{Impacts of land use for BECCS}

Land carbon stocks are influenced both by direct land use change (dLUC) involved in switching to the BECCS crop and from secondary impacts (e.g. in shifting demand for food to new areas) which lead to indirect land use change (iLUC). It is particularly difficult to summarize the potential emissions from iLUC, as its impact and extent is a function of spatial ecology, macro-scale economics, and type of biomass feedstock considered. So that iLUC can only be modelled and not measured directly. Second generation biofuels have been reported to have a median carbon loss of $5 \mathrm{gCO}_{2}$-eq/MJ, although sequestration is possible mainly in marginal areas, where perennial crops (such as switchgrass (Panicum virgatum), miscanthus (Miscanthus $x$ giganteus) and Arundo donax) can increase belowground carbon content leading to negative emissions of $-12 \mathrm{gCO}_{2}$-eq/MJ (Valin et al., 2015). Pellets from forest residues have been reported to have a mean loss of $17 \mathrm{gCO}_{2}$-eq/MJ biofuel due to lower build-up of soil organic carbon stocks (Valin et al., 2015). Straw and stover could have losses varying from 2 to $3 \mathrm{gCO}_{2}$-eq/MJ biofuel (Overmars et al., 2015), while for cereal straw they vary from 0 to $16 \mathrm{gCO}_{2}$-eq/MJ biofuel (Valin et al., 2015) (see Table 1).

\section{Balancing biomass supply and demand}

The deployment of BECCS is ultimately reliant on the availability of sufficient, sustainably sourced, biomass for an active CCS industry operating at scale and a favourable policy and commercial environment to incentivise these investments (Boysen, Lucht \& Gerten, 2017). IAM scenarios aimed at keeping warming below $2{ }^{\circ} \mathrm{C}$ include global demand for sustainable biomass for BECCS ranging from $60 \mathrm{EJ} /$ year up to more than $500 \mathrm{EJ} /$ year (Fuss et al., 2018). The supply of biomass needs to be sufficient to either provide for centralised power stations or distributed energy systems, such as combined heat and power (CHP) stations. There are 
also opportunities to capture $\mathrm{CO}_{2}$ from other sources such as ethanol biorefineries using first generation crops (Sanchez et al., 2018). The two most important factors determining the biomass supply for BECCS are land availability and land productivity. These factors are in turn determined by competing uses of land and a myriad of environmental and economic considerations (Searle \& Malins, 2014). Published estimates of the potential for biomass supply vary widely, due mainly to the mixture of methodologies, assumptions and datasets employed (Batidzirai et al., 2012). Different estimates derive in part from differing utilisation of the same data collated by the Food and Agriculture Organisation (FAO), and from the use of different assumption on the spatial and temporal factors affecting biomass potential production. Furthermore, because in the FAO data-set there is a paucity of data for some regions, such as Africa, the lack of robust, reliable and high resolution information make global spatial biomass assessments difficult to model.

The potential sources of biomass for BECCS range from harvested residues from first generation food crops to forests, managed short-rotation coppice such as willow and poplar, and second generation biomass crops such as perennial rhizomatous grasses. The advantage of the second generation crops is that they can produce usable energy with less than $10 \%$ the energy inputs of first generation food crops, and lower water and nutrient requirements. However, the viability of achieving the highest yields demonstrated in experimental plots over large areas and many different types of soils has not yet been demonstrated. For example Searle \& Mallins (2015) reviewed the yields of five major energy crops (Miscanthus, Switchgrass, Poplar, Willow, and Eucalyptus) all of which had produced high yields in small, intensively managed trials. However, yields were significantly lower in semi-commercial scale trials, due largely to biomass losses with drying and harvesting inefficiency under real world conditions.

Recent studies provide a large range for the global technical potential of biomass supply for 2050, ranging from $\sim 30$ to over 1,000 EJ/yr (Table 1). However the higher levels are considered implausible either because the estimates of available land are too optimistic or yield expectations are inflated by extrapolations from pilot-based studies to large areas of less productive marginal and severely degraded land (Smith \& Torn, 2013; Smith et al., 2014). Furthermore the ability of degraded and marginal land to produce economic yields without the use of expensive fertilisers and irrigation is vastly overestimated (Field, Campbell \& Lobell, 2007). In addition, relating the unevenly distributed biomass supply to the amount of $\mathrm{CO}_{2}$ that can be stored geologically (Hendricks et al., 2004) is complex as the available regional information does not account for the possibility that $\mathrm{CO}_{2}$ storage capacity may also be unevenly distributed within a given region (Muri, 2018).

The global land areas needed for the deployment of BECCS by 2100 have been estimated to range from 380 to 700 Mha (Smith et al., 2015). The upper bounds correspond to three times the world's harvested land for cereal production, twice the current water use for agriculture and 20 times the current US annual fertiliser use. The reason why the range is so 
large, revolves around differences in the definition of marginal land that is abandoned or severely degraded. Also, while there is evidence that the area of abandoned land has been increasing, with the FAO Landsat analysis indicating that across the tropics 77 Mha of cropland and pasture had been abandoned either temporarily or permanently during the 1990s (FAO, 2001; Gibbs et al., 2010), the productivity of this land is very low.

As well as abandoned land, it seems that globally there is a sizable area of land that is used for agriculture but which makes a small contribution to food production and could be used for biomass production (approximately $600 \mathrm{Mha}$ ) (Alexandratos and Bruinsma, 2012, Mason et al., 2015). Considering only low productivity cropland with terrain slope $\geq 20 \%$ (i.e. disadvantaged agricultural areas), Albanito et al. (2016) suggested that the global land suitable for bioenergy would be approximately $250 \mathrm{Mha}$, which could generate up to $318 \mathrm{EJ}$ of primary energy.

Spatially explicit studies on the availability of biomass for BECCS are limited to the USA and UK. Baik et al., (2018) reported that by 2020 in the US up to $230 \mathrm{Mt}$ of lignocellulosic biomass could be available annually producing as much as $400 \mathrm{Mt} \mathrm{CO}_{2} /$ year for sequestration in BECCS. The UK has a theoretical storage $\mathrm{CO}_{2}$ capacity of $78 \mathrm{GtCO}_{2}$ with $50 \%$ confidence (Bentham et al., 2014), and previous research reported that BECCS could mitigate between 4.5 and $55 \mathrm{MtCO}_{2} /$ year and approximately $1.5 \mathrm{Mha}$ could be made available to bioenergy crops (ETI, 2016; Smith et al., 2016). However, considering only the low quality grade agricultural land available to produce an environmentally and economically sustainable supply of biomass to the power sector, Albanito et al. (2019) reported that only 0.4 to 0.5 Mha would be available across Great Britain.

\section{Are biomass for BECCS ambitions sustainable?}

In recent years the widely accepted criteria for a sustainable biomass supply have evolved to ensure that the biomass: (i) is not redirected from food or animal feed purposes, (ii) does not reduce the ecological functioning of the land, (iii) is grown on marginal land not suitable or economically attractive for food crop production, and (iv) is utilised locally (within 50 $\mathrm{km}$ ) to limit transport costs (Lewandowki, 2015).

Smith et al., (2015) make it clear that bioenergy systems deployment needs to balance a range of environmental, social, and economic objectives that are not always fully compatible. The effectiveness and consequences of bioenergy development depends on: (i) the technology used, (ii) the location, scales, and pace of implementation (iii) the land used, i.e. forest, grassland, crop lands, and marginal land, including how they displace existing land use, and (iv) the business models and practices adopted. The conclusion is that estimates of availability for the future depends on the evolution of a multitude of social, political, and economic factors including land tenure and regulation, trade, and technology (Smith et al., 2015; Bui et al., 2018). 
An additional and rapidly emerging issue is the realisation that there will be competing demands for biomass to provide the feedstock of a rapidly growing bio-economy (Dahmen et al., 2019). Using biomass for energy is a high volume, low value operation while biomass used for the production of bio-based chemicals and materials, which will be essential if the demands to remove non-degradable plastics from the environment are to be met, has a much higher value.

We suggest that further work is thus required to quantify the sustainable capabilities for BECCS as a NET. This should demonstrate that, before being given priority in future climate change reduction strategies, the risks can be managed effectively through not only technical means but also international governance and the impacts that NETs will have on sustainable development goals and equity issues between nations (Fajady \& Mac Dowell, 2017; Fuhrman et al., 2019). Moreover, energy policy should not overlook the inherently low efficiency of exploiting photosynthesis (the basic process driving conversion of $\mathrm{CO}_{2}$ to biomass) for energy, since the amount of electricity which can be produced from a hectare of land using Photo Voltaic (PV) is at least 50-100 times that of biomass (Baldocchi \& Penuelas, 2018). Reducing uncertainty in the outcomes is crucial to increase the robustness of decisions that use integrated assessment models as inputs and more sensitivity analyses should be made in order to understand the implications of various parameters and assumptions. Models to assess the impacts of biomass for BECCS on GHG concentrations and climate change require details of land use change impacts, including long term nutrient and productivity changes, supply chain emissions from biomass harvesting, processing, and transport, combustion efficiencies of and related emissions of different fuels, and changes in albedo and other biophysical processes that alter how GHGs affect the climate.

\section{Conclusion}

The International Energy Agency predicts that bioenergy could become the most important renewable energy by 2030 (IEA, 2016). However, this depends on the implementation of renewable energy strategies of key countries for the near-term deployment of BECCS at a scale to meet significant energy demands. The production of biomass feedstocks are directly linked to communities, farms, forests, and ecosystems from which resources are extracted. Therefore, bioenergy production for BECCS has potential for significant social and justice implications which could severely impede the deployment of BECCS at scale. This conflicts with the suggestion that BECCS may be an early-use NET, which allows time for the development of other more technically challenging NETs.

It is likely that NETs deployment at the huge scales envisaged in many scenarios could greatly exceed our collective ability to manage carbon cycle flows, thereby risking doing more harm than good. The viability of BECCS as a NET option depends on the choices made throughout the supply chain. Land competition for food production and greenhouse gas emissions associated with biomass cultivation, harvesting, and processing cast doubt on the ability of $\mathrm{BECCS}$ to result in net removal of $\mathrm{CO}_{2}$ from the atmosphere. Assessment of water, 
land and carbon intensity of biomass supply chain and conversion technology is vital before supporting the large scale deployment of BECCS. Furthermore, the impacts of large scale BECCS on terrestrial biodiversity have received little consideration so far (Heck et al., 2018). All current evidence shows that the anticipated high variability in the effectiveness of BECCS $\mathrm{CO}_{2}$ removal illustrates the need for a case by case analysis. The policy implication is that regulating and attributing value to these systems will have to be integrated to regional specificity, but how this might be achieved remains an open question (Reid, Ali \& Field, 2019).

In conclusion, all available evidence points to a high variability in the possible outcomes of a BECCS project, both in terms of cumulative net carbon removal over the facility's lifetime, and also the time required for a given facility to start removing $\mathrm{CO}_{2}$ from the atmosphere. Furthermore, significant risks exist of perverse outcomes where the net effect is to increase emissions (Fridahl \& Lehtveer, 2018; Heck et al., 2018). Key factors which favour improved carbon efficiencies for biomass production are: limiting the impacts of direct and indirect land use changes, using carbon neutral power and organic fertilizers, prioritizing sea and rail over road transport, increasing the use of carbon negative fuels, and exploiting alternative biomass processing options; e.g. natural drying. However, the prospects of these achieving the anticipated negative emissions by BECCS in the near term are very uncertain and support the view that BECCS are not currently fit for purpose (Fuss et al., 2018).

\section{Acknowledgements:}

MBJ received funding from The Environmental Protection Agency, Ireland, Research Programme 2014-2020, Grant No. 2016-CCRP-MS.36

\section{References:}

Albanito, F., Hastings, A., Fitton, N., Richards, M., Martin, M., et al. (2019). Mitigation potential and environmental impact of centralized versus distributed BECCS with domestic biomass production in Great Britain. GCB Bioenergy, 11, 1234-1252.

Albanito, F., Beringer, T., Corstanje, R., Poulter, B., Stephenson, A., Zawadzka, J. \& Smith., P. (2016). Carbon implications of converting cropland to bioenergy crops or forest for climate mitigation: A global assessment. Global Change Biology and Bioenergy, 8, 81-95.

Alexandratos, N., \& Bruinsma, J. (2012). World agriculture towards 2030/2050: The 2012 revision. ESA Working paper No. 12-03. Rome, FAO.

Anderson, K., \& Peters, G. (2016). The trouble with negative emissions. Science, 354, 182183. 
Baik, E., Sanchez, D.L., Turner, P. A., Mach, K.J., Field, C.B., \& Benson, S. M. (2018). Geospatial analysis of near-term potential for carbon-negative bioenergy in the United States. PNAS, 115, 3290-3295.

Baldocchi, D., \& Penuelas, J. (2018). The physics and ecology of mining carbon dioxide from the atmosphere by ecosystems. Global Change Biology, 25, 1191-1197.

Batidzirai, B. Smeets, E., \& Faaij, A. (2012). Harmonising bioenergy resource potentials Methodological lessons from review of state of the art bioenergy potential assessments. Renewable and Sustainable Energy Reviews, 16, 6598 - 6630.

Bentham, M., Mallows, T., Lowndes, J., \& Green, A. (2014). $\mathrm{CO}_{2}$ storage evaluation database

Bentsen, N.S., (2017). Carbon debt and payback time - Lost in the forest? Renewable and

Beringer, T., Lucht, W., \& Schaphoff, S. (2011). Bioenergy production potential of global biomass plantations under environmental and agricultural constraints. GCB Bioenergy, 3, 299-312.

Berndes, G., Hoogwijk, M., \& van den Broek, R. (2003). The contribution of biomass in the future global energy supply: a review of 17 studies. Biomass and Bioenergy, 25, 1-28.

Boysen, L. R., Lucht \& W, Gerten, D. (2017). Trade-offs for food production, nature conservation and climate limit the terrestrial carbon dioxide removal potential. Global Change Biology, 23, 4303-4317.

Brandao, M., Kirschbaum, U. F., Cowie, A. L., \& Vedel Hjuler, S. (2018). Quantifying the climate change effects of bioenergy systems: comparisons of 15 impact assessment methods. GCB Bioenergy, 11, 727-743.

Bui, M., Adjiman, C. S., Bardow, A., Anthony, E. J. et al., (2018). Carbon capture and storage (CCS): the way forward. Energy and Environmental Science, 11, 1062-1176.

Dahmen, N., Lewandowski, I., Zibek, S., \& Weidtmann, A. (2019). Integrated lignocellulosic value chains in a growing bioecononmy: Status quo and perspectives. GCB Bioenergy, 11, 107-117. 
Dornburg, V., van Vuuren, D., van de Ven, G., Langeveld, H., Meeeusen, M. et al. (2010). Bioenergy revisited: key factors in global potentials of energy. Energy and Environmental Science, 3, 258-267.

EASAC. (2018). Negative emission technologies: what role in meeting Paris agreement targets? Policy Report 35. www.easac.eu

Energy Technologies Institute (ETI). (2016). The evidence for deploying bioenergy with CCS (BECCS) in the UK. Retrieved from https://d2umxnkyjne36n.cloudfront.net/insightReports/The-Evidence-for-DeployingBioenergy-with-CCS-in-the-UK.pdf?mtime $=20161107110603$

Food and Agriculture Organization. (2001). Global Forest resources assessment 2000. FAO Forestry Paper 140 (p. 479). Rome, Italy.

Fajardy, M., \& Mac Dowell, N. (2017). Can BECCS deliver sustainable and resource efficient negative emission? Energy Environ. Sci. 10, 1389-1426.

Field, C.B., Campbell, J. E., \& Lobell, D.B. (2007). Biomass energy: the scale of the potential resource. Trends in Ecology and Evolution, 23, 65-72.

Fridahl, M., \& Lehtveer, M. (2018) Bioenergy with carbon capture and storage (BECCS): Global potential, investment preferences, and deployment barriers. Energy Research \& Social Science, 42, 155-166.

Fuhrman, J., McJeon, H., Doney, S. C., Shobe, W., \& Clarens, A. F. (2019) From zero to hero?; Why integrated assessment modelling of negative emissions technologies is hard and how we can do better. Frontiers in Climate, 1, Article 11 doi:10.3389/fclim.2019.00011

Fuss, S., Canadell, J. G., Peters, G. P., Tavoni, M., Andrew, R. M. et al. (2014). Betting on negative emissions. Nature Climate Change, 4, 850-853.

Fuss, S., Lamb, W. F., Callaghan, M. W., Hilaire, J., Creutzig, F. et al. (2018). Negative emissions - Part 2: Costs, potentials and side effects. Environmental Research Letters, 13, 063002.

Gibbs, H. K., Ruesch, A. S., Achard, F., Clayton, M. K., Holmgren, P., Ramankutty, N., et al. (2010). Tropical forests were the primary sources of new agricultural land in the 1980s and 1990s. Proceedings of the National Academy of Sciences, 107(38), 16732-16737.

Gough, C., Garcia-Freites, S., Jones C, \& Manders, S. (2018). Challenges to the use of BECCS as a keystone technology in pursuit of $1.5^{\circ} \mathrm{C}$. Global Sustainability, 1, e5, 1-9. 
Haberl, H., Beringer, T., Bhattacharya, S. C., Erb, K-H., \& Hoogwijk, M. (2010). The global technical potential of bio-energy in 2050 considering sustainability constraints. Current Opinion in Environmental Sustainability, 2, 394-403.

392

393

394

Hastings, A. (2017). Bioenergies impacts on Natural Capital and Ecosystem Services: A comparison of biomass and coal fuels. In. Z. Qin, U. K. Mishra, \& A. Hastings (Eds.) Bioenergy and Land Use Change (pp. 83-97) AGU/Wiley.

Heck, V., Gerten, D., Lucht, W., \& Popp, A. (2018) Biomass-based negative emissions difficult to reconcile with planetary boundaries. Nature, Climate Change doi.org/10.1038/s41558017-0064-y

IEA (2016). Energy Technology Perspectives 2016: Towards Sustainable Urban Energy Systems. Paris. OECD/IEA

IPCC (2019). Climate change and land. An IPCC special report on climate change, desertification, land degradation, sustainable land management, food security, and greenhouse gas fluxes in terrestrial ecosystems. P.R. Shukla, J. Skea, E. Calvo Buendia, V. Masson-Delmotte, H.-O. Pörtner, D. C. Roberts, P. Zhai, R. Slade, S. Connors, R. van Diemen, M. Ferrat, E. Haughey, S. Luz, S. Neogi, M. Pathak, J. Petzold, J. Portugal Pereira, P. Vyas, E. Huntley, K. Kissick, M, Belkacemi, J. Malley, (eds.). In press.

Kato, E., \& Yamagata, Y. (2014) BECCS capability of dedicated bioenergy crops under a future land-use scenario targeting net negative carbon emissions. Earth's Future, 2, 421-439.

Kemper, J. (2015). Biomass and carbon dioxide capture and storage: a review. International Journal of Greenhouse Gas Control, 40, 401-430.

Lewandowski, I. (2015). Securing a sustainable biomass supply in a growing bioeconomy. Global Food Security, 6, 34-42. doi: 10.1016/j.gfs.2015.10.001.

Mason, P.M., Glover, K., Smith, J.A.C., Willis, K.J., Woods, J., \& Thompson, I.P. (2015). The potential of CAM crops as a globally significant bioenergy resource: moving from 'fuel or food' to 'fuel and more food'. Energy \& Environmental Science, 8, 2320-2329.

McKechnie, J., Colombo, S., Chen, J., Mabee, W., \& Maclean, H. (2011). Forest bioenergy or forest carbon? Assessing trade-offs in greenhouse gas mitigation and wood-based fuels. Environmental Science and Technology, 45, 789-795.

Madsen, K., \& Bentsen, N. S. (2018). Carbon debt payback time for a biomass fired CHP plant - A case study from Northern Europe. Energies, 11, 807; doi:10.3390/en11040807. 
Melillo, J. M., Reilly, J. M., Kicklighter, D. W., Gurgel, A. C., Cronin, T. W. et al. (2009).

Minx, J. C., Lamb, W., Callaghan, M., Bornmann, L., Fuss, S. et al. (2017). Fast growing research on negative emissions. Environmental Research Letters, 12, 035007.

Muri, H. (2018). The role of large-scale BECCS in the pursuit of the $1.5^{\circ} \mathrm{C}$ target: an earth system model perspective. Environmental Research Letters, 13, 044010.

National Academies of Sciences (NAS) (2019). Negative Emissions Technologies and Reliable Sequestration: A Research Agenda. Washington, DC: The National Academies Press. doi: https://doi.org/10.17226/25259.

Nemet, G. F., Callaghan, M. W., Creutzig, F., Fuss, S., Hartmann, J. et al. (2018). Negative emissions -Part 3: Innovation and upscaling. Environmental Research Letters, 13, 063003.

Odeh, N. A. and Cockerill, T.T. (2008). Life cycle GHG assessment of fossil fuel power plants with carbon capture and storage. Energy Policy 36, 367-80.

Overmars, K., Edwards, R., Padella, M., Prins, A. G., \& Marelli, L. (2015). Estimates of indirect land use change from biofuels based on historical data. Luxembourg: Publications Office of the European Union.

453

Reid, W. V., Ali, M. K., \& Field, C. B. (2019). The future for bioenergy. Global Change Biology Doi: $10.1111 / G C B .14883$.

456

Röder, M., Whittaker, C., \& Thornley, P. (2015). How certain are greenhouse gas reductions from bioenergy? Life cycle assessment and uncertainty analysis of wood pellet-to-electricity supply chains from forest residues. Biomass and Bioenergy, 79, 50-63.

Roder, M., \& Thornley, P. (2016). Bioenergy as climate change mitigation option within a $2{ }^{\circ} \mathrm{C}$ target - uncertainties and temporal challenges of bioenergy systems. Energy, Sustainability and Society, 6, doi: 10.1186/s13705-016-0070-3.

465

Sanchez, L., Johnson, N., McCoy, S. T., Turner, P.A., Mach, K. J. (2018) Near-term deployment of carbon capture and sequestration from biorefineries in the United States. PNAS, 115, 4875-4880. 
Searle, S., \& Malins C. (2015). A reassessment of global bioenergy potential in 2050. GCB

Smith, L. J., \& Torn, M. S., (2013). Ecological limits to terrestrial biological carbon dioxide

Smith, P., Davis, S. J., Creutzig, F., Fuss, S., Minx, J. et al. (2015). Biophysical and economic

Smith, P., Haszeldine, R. S., Smith, S. M. (2016). Preliminary assessment of the potential for, and limitations to, terrestrial negative emission technologies in the UK. Environmental Science: Processes \& Impacts, 18, 1400-1405

485

Smith, P., Bustamante, M., Ahammad, H., Clark, H., Dong, H. et al. (2014). Agriculture, Forestry and Other Land Use (AFOLU). In: Climate Change 2014: Mitigation of Climate Change. Contribution of Working Group III to the Fifth Assessment Report of the Intergovernmental Panel on Climate Change. Edenhofer, O., R. Pichs-Madruga, Y. Sokona, E. Farahani, S. Kadner, K. Seyboth, A. Adler, I. Baum, S. Brunner, P. Eickemeier, B. Kriemann, J.

Sterman, J. D., Siegel, L., \& Rooney-Varga, N. (2018). Does replacing coal with wood lower $\mathrm{CO}_{2}$ emissions? Dynamic lifecycle analysis of wood bioenergy. Environmental Research Letters, 13, 015007

Tanzer, S.E., \& Ramirez, A. (2019). When are negative emissions negative emissions? Energy and Environmental Science, 12, 1210-1218.

500

Woods, J., Lynd, L. R., Laser, M., Batistella, M., Victoria, D. C., Kline, K., \& Faaij, A. (2015). Land and bioenergy. In: Bioenergy \& Sustainability: Bridging the Gaps 72. SCOPE, Paris. France, 258-301, (ISBN 978-2-9545557-0-6). (2015). The land use change impact of biofuels consumed in the EU Quantification of area and greenhouse gas impacts, ECOFYS, Netherlands B.V. www.ecofys.com

Vaughan, N. E., \& Gough, C. (2016). Expert assessment concludes negative emissions scenarios may not deliver. Environmental Research Letters, 11(9), 095003 

D. P. (2018) Evaluating the use of biomass energy with carbon capture and storage in low emission scenarios. Environmental Research Letters, 13, 044014

Table 1. Published estimates of global bioenergy technical production potential (i.e. amount of biomass energy that can be supplied globally given current expectations on technology, food demand and environmental constraints), and potential indirect land use change (iLUC) GHG emissions from the demand for food crops in new areas (iLUC) due to the conversion of current croplands to biomass feedstock production.

\begin{tabular}{|l|l|l|}
\hline Reference & Bioenergy Production Potential & $\begin{array}{l}\text { Comments } \\
\text { 'Scientific studies required in order } \\
\text { to be more precise' }\end{array}$ \\
\hline Haberl et al. (2010) & $160-270 \mathrm{EJ} / \mathrm{yr}$ in 2050 & \\
\hline Dornburg et al. (2010) & $200-500 \mathrm{EJ} / \mathrm{yr}$ in 2050 & Review of 17 studies \\
\hline Berndes et al. (2003) & $100->400 \mathrm{EJ} / \mathrm{yr}$ in 2050 & Used LPJmL DGVM model \\
\hline Beringer et al. (2011) & $130-270 \mathrm{EJ} / \mathrm{yr}$ in 2050 & \\
\hline Rogier et al. (2012) & $793 \mathrm{EJ} / \mathrm{yr}$ currently & 'most likely range' \\
\hline Kemper et al. (2015) & $50->1000 \mathrm{EJ} / \mathrm{yr}$ currently & \\
\hline Fuss et al. (2018) & $60-1548 \mathrm{EJ} / \mathrm{yr}$ in 2050 & Production system \\
\hline Reference & $\mathrm{GHG}$ emissions from iLUC & Forest residues \\
\hline Valin et al. (2015) & $17 \mathrm{gCO}_{2}$-eq/MJ & Cereal straw \& stover \\
\hline Overmars et al. (2015) & $2-3 \mathrm{gCO}_{2}$-eq/MJ & Cereal straw \& stover \\
\hline Valin et al. (2015) & $0-16 \mathrm{gCO}_{2}$-eq/MJ & Swichgrass \& miscanthus \\
\hline Valin et al. (2015) & $-12 \mathrm{gCO}_{2}$-eq/MJ & Eucalyptus, swichgrass \& poplar \\
\hline Melillo et al. (2009) & $275-285 \mathrm{gCO}$-eq/MJ & \\
\hline
\end{tabular}

Figure Legend:

Figure 1. The simplistic vision of BECCS is that one ton of $\mathrm{CO}_{2}$ captured in the growth of biomass would equate to one ton of $\mathrm{CO}_{2}$ sequestered geologically, which we can regard as a carbon efficiency of 1 (i.e. Gate to Gate with carbon neutrality). This simplistic concept of carbon neutrality in the bioenergy debate, however, is far from the reality. Depending on the different technology assessments boundaries applied to the BECCS scenario (e.g. Cradle to Grave), GHG emissions are emitted throughout the biomass supply-chain reducing the 

carbon efficiency of BECCS to less than 50\% (EASAC, 2018). In bioenergy systems, indirect land use change (iLUC) also needs to be included to achieve a full picture of the system 540 impacts (i.e. Cradle to Grave with iLUC).

541

542 